\title{
Preliminary Stress Corrosion Cracking Modeling Study of a Dissimilar Material Weld of Alloy (Inconel) 182 with Stainless Steel 316 in Pressurized Water Nuclear Reactor
}

\author{
Omar Fernandes Aly $^{1, *}$, Miguel Mattar Neto ${ }^{1}$ and Mônica Maria de Abreu Mendonça \\ Schvartzman ${ }^{2}$
}

${ }^{1}$ Nuclear Engineering Center, IPEN/CNEN-USP, São Paulo, Brazil

${ }^{2}$ CDTN/CNEN-UFMG, Belo Horizonte, Brazil

\begin{abstract}
Dissimilar welds (DW) are normally used in many components junctions in structural project of PWR (Pressurized Water Reactors) in Nuclear Plants. One had been departed of a DW of a nozzle located at a Reactor Pressure Vessel (RPV) of a PWR reactor, that joins the structural vessel material with an A316 stainless steel safe end. This weld is basically done with Inconel/Alloy 182 with a weld buttering of Inconel/Alloy 82 . It had been prepared some axial cylindrical specimens retired from the Alloy 182/A316 weld end to be tested in the slow strain rate test machine located at CDTN laboratory. Based in these stress corrosion susceptibility results, it was done a preliminary semi-empiric modeling application to study the failure initiation time evolution of these specimens. The used model is composed by a deterministic part, and a probabilistic part according to the Weibull distribution. It had been constructed a specific Microsoft Excel worksheet to do the model application of input data. The obtained results had been discussed according with literature and also the model application limits.
\end{abstract}

Keywords: Dissimilar Welds, Pressurized Water Stress Corrosion Cracking, Semi-Empiric-Probabilistic Modeling, Slow Strain Rate Tests, Weld Nickel Alloys (Inconel) 82/182.

\section{INTRODUCTION}

Dissimilar welds are normally used in many components junctions in structural project of PWR in Nuclear Plants. One had been departed of a DW of a nozzle located at a RPV of a PWR reactor, that joins the structural vessel material with an A316 stainless steel safe end. This weld is basically manufactured with Alloy 182 with a weld buttering of Alloy 82 . It had been prepared some axial cylindrical specimens retired from the Alloy 182/A316 weld end to be tested in the slow strain rate test machine located at CDTN laboratory (Figure 1).

In this paper is done a preliminary modeling and analysis of primary data obtained at CDTN-Brazilian Nuclear Development of Nuclear Technology, related to testing of Inconel 182 for evaluation of primary water stress corrosion cracking (PWSCC) in DW of Spanish Lemoniz reactor (which never entered operation). The objective of these tests is to evaluate the PWSCC in different positions of the dissimilar welding existing in the cold leg of the reactor (Figure 1), at two

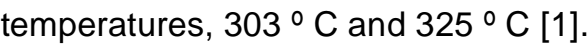

*Address correspondence to this author at the Energy and Nuclear Research Institute- IPEN/CNEN-USP, Nuclear Engineering Center, Av. Lineu Prestes 2242- São Paulo University Campus, 05508-000 São Paulo-SP, Brazil;

Tel: 55(11) 3133-9404; Fax: 55(11) 3133-9423;

E-mail: ofaly1@gmail.com, ofaly@ipen.br
The CDTN tests of Inconel/Alloy 182 were taken at different temperature conditions. Two tests at $\mathrm{T}=303^{\circ} \mathrm{C}$ were completed [1].

In the SSRT developed at CDTN it has been used Inconel specimens, and test standard practice according ASTM-G-129-00. Alloy 182 is basically 67 $\mathrm{Ni}-15 \mathrm{Cr}-8 \mathrm{Fe}$.

The Slow Strain Rate Test (SSRT) had been developed to susceptibility evaluation of stress corrosion cracking in a fixed environment. It is a particular case of the tensile test, realized through slow strain imposed to the specimen immersed in the actual environment condition. Parameters related to the material ductility variation (failure time, plastic deformation, and ultimate tensile strength) are obtained at the stress versus strain curves, plus the visual observation of affected fractured region: the fracture morphology; these are used as material strength to SCC at the considered environment. To reproduce the actual environment of high temperature water, the equipment has an autoclave for high pressure and temperature simulation of that condition. In this case, it was used cylindrical specimens extracted according to the Figure 1. These results should be compared with the results of a similar test conducted at a neutral environment (as for example, $\mathrm{N}_{2}$ ): the strength or the susceptibility should be analized, and the effects not caused by SCC should be eliminated [2]. The strain 


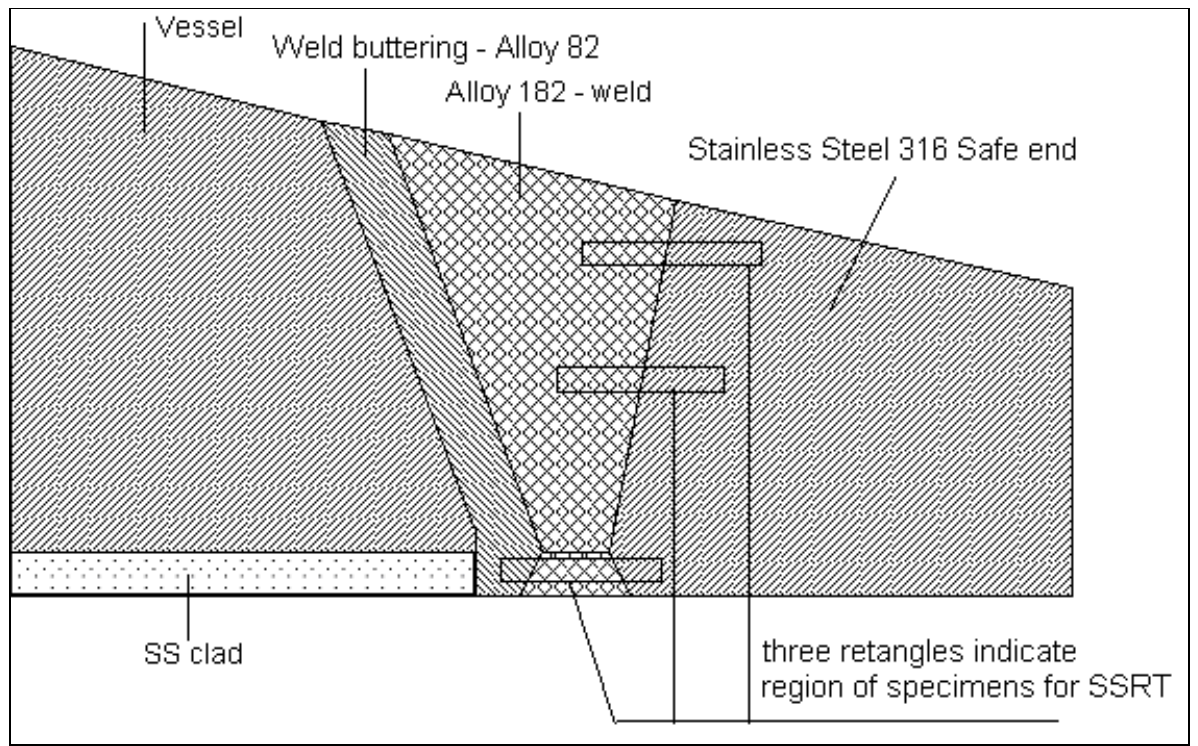

Figure 1: Sketch of Dissimilar Weld of reactor \#1 from Lemoniz [1].

Table 1: Deterministic Modeling Deviation Related to CDTN Experimental Data [1]

\begin{tabular}{|c|c|c|c|c|c|}
\hline $\begin{array}{c}\text { CDTN } \\
\text { Test } \\
\text { Number }\end{array}$ & Test Temperature $\left({ }^{\circ} \mathrm{C}\right)$ & $\begin{array}{c}\sigma \text { Average } \\
\text { (MPa)-Admitted } \\
\text { Values( }\left(^{*}\right)\end{array}$ & $\begin{array}{c}\text { Experimental Results } \\
\text { (Days) }\end{array}$ & $\begin{array}{l}\text { Modeling Results } \\
\text { (Days) }\end{array}$ & Deviation (\%) \\
\hline $19,20,21$ & 303 & 450 & $\begin{array}{c}14.3 \text { (average or three } \\
\text { experiments) }\end{array}$ & 14.30 & 0.0 \\
\hline 25,26 & 315 & 450 & $\begin{array}{l}8.23 \text { (average for two } \\
\text { experiments) }\end{array}$ & 9.15 & 10.0 \\
\hline 28 & 325 & 450 & 4.7 & 5.28 & 12.3 \\
\hline 29 & 323 & 500 & 5.4 & 2.76 & 48.9 \\
\hline 22 & 324 & 450 & 9.2 & 5.51 & 40.1 \\
\hline 24 & 323.5 & 450 & 10.5 & 5.64 & 46.3 \\
\hline
\end{tabular}

Note $\left(^{*}\right)$ : Admitted from the Stress vs. Strain results to the CDTN tests 19,20 e 29

rate used for the study case was normally around 3.0x $10^{-7} \mathrm{~s}$. The results of tests could be arranged and compared as in Table 1, and the first observation is that there are not deterministic results. The SCC is a stochastic process, and based in these data, it was done a preliminary modeling, showed in the next Section.

\section{MODELING THE EXPERIMENTAL DATA}

For the modeling, it has been departed from three tests realized at T equal to $303^{\circ} \mathrm{C}$.

It was used the semi-empiric model according to Eq. (1), adapted from reference [3].

$t_{i}=A \times \sigma^{n} \times \exp \left(\frac{Q}{R T}\right)$ with $t_{i}=$ initiation time (days), $\sigma=$ stress (MPa), $T=$ absolute environment temperature $(\mathrm{K}) ; Q=$ activation energy $(\mathrm{kcal} / \mathrm{mol}) ; \quad R=$ universal gas constant $=0.001987 \mathrm{kcal} / \mathrm{mol} ; A=$ parameter to be adjusted according other dependences such as material treatment, environment composition including hydrogen content.

1) First, it has been necessary to research the most probable value to Alloy 182 activation energy which has been found as $Q_{A 182}=31 \mathrm{kcal} / \mathrm{mol}$ at $\mathrm{T}=325^{\circ} \mathrm{C} \mathrm{[4]}$;

2) It has been necessary to evaluate the stress exponent " $n$ ", through data correlating stress with initiation time: the unique article localized where is there a direct correlation between these two parameters was the reference wrote by Scott et al. [5]: the test procedure in this article is different from the used in CDTN, but the estimative is reasonable for a 


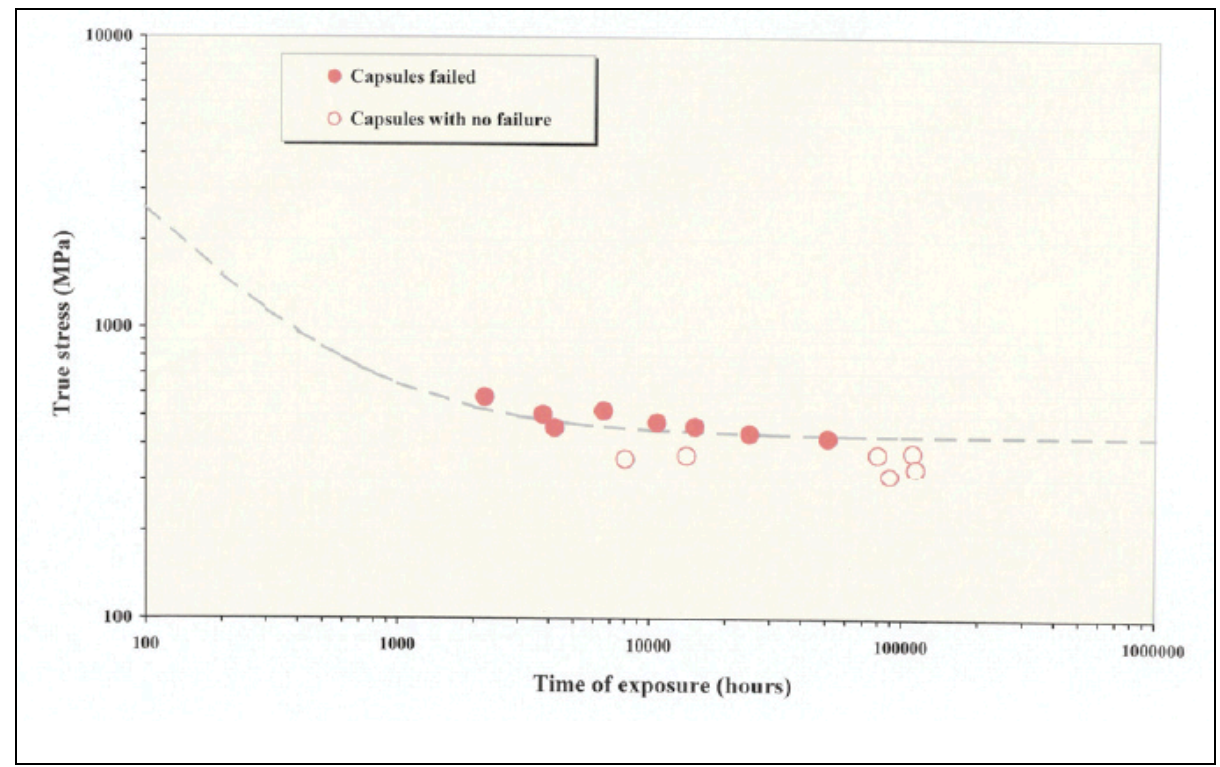

Figure 2: Initiation time/time to cracking of test specimens (capsules) with an Alloy 182 weld in function of the applied/tensile stress [5].

preliminary modeling. It was used the Figure 4 from [5], here reproduced as Figure 2.

Based in it, the exponent " $n$ " was equal to -7 , which is according to other literature references such as [6];

3) The initiation time considered in Equation (1) was the average time of three CDTN experiments (more details in [1]). Thus, $t_{i}=(15.1+14.3+13.5) / 3=14.3$ days;

4) The considered stress " $\sigma$ " was about $450 \mathrm{MPa}$, extracted from stress vs. strain graphics provided for two CDTN tests (see other details and attached files provided by CDTN in [1]);

5) Thus, the resulting semi-empiric modeling for the Alloy 182 CDTN tests is represented by Eq. (2).

$t_{i}^{A 182}=92176093.62 \times \sigma^{-7} \times \exp \left(\frac{15601.41}{T}\right)$

where: $t_{i}{ }^{A 182}=$ PWSCC initiation time for Alloy 182 (days), $\sigma=$ stress $(\mathrm{MPa}), \mathrm{T}=$ absolute environment temperature $(\mathrm{K})$.

6) This modeling was applied to other CDTN tests at other temperatures, and the results are in Table $\mathbf{1 .}$

The larger deviations were in the CDTN tests 22, 24 and 29. In the test 29 if was admitted $\sigma=450 \mathrm{MPa}$, the resulting modeling value grows to 5.4 days, near the experimental result.
7) The deviations between modeling and experimental are not uncommon in the SCC case: as the SCC process is multiple variable dependent, data scattering is frequent. Thus, is not easy to apply deterministic models, which should do after a very hard data filtering: this should consider only data rigorously collected at same condition, and that is not easy. A practical solution is to consider a probabilistic regression together with a semi-empiric numeric modeling. For this case is normally used the Weibull distribution as showed in Eq. (3) [3].

$F=1-\exp \left[-0.0101\left(\frac{t}{t_{1 \%}}\right)^{b}\right]$

where: $F=$ accumulated fraction of population of components under consideration all susceptible to the same failure mode that experience PWSCC; $t=$ time; $b=$ Weibull slope, a fitted parameter determined by the analysis of failure data; $t_{1 \%}=$ time which corresponds to the time of failure when $63.2 \%$ of the components had experienced PWSCC.

Then it was done a probabilistic regression of CDTN data, through an Excel worksheet file (attached file "Ensaios Liga 182- CDTN_Modelagem Preliminar.xls" at reference [1]).

8) One of the graphics resulted is showed in the Figure 3. It was considered a regression of experimental data at temperature of $303^{\circ} \mathrm{C}$ : the number of tests was only three, despite the least number of 


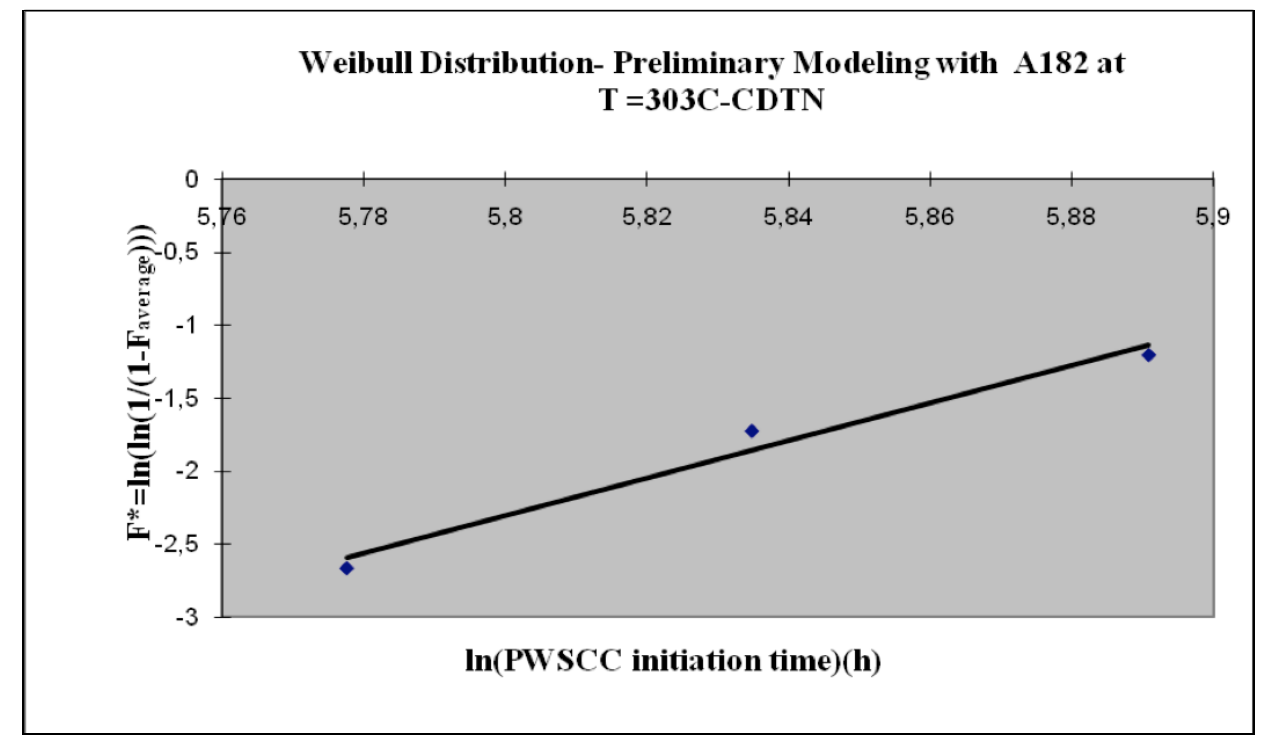

Figure 3: Excel graphic of the transformed $\mathrm{F}^{\star}$ in function of the initiation time, adjusted by mean of the Weibull distribution (Note: Numbers in scales are in Brazilian notation) [1].

recommended tests are seven [3]. Thus, it was not detected data scattering in this case, which is common in the Alloy 182 SCC tests. The adjusted line showed that in this case it is practically a deterministic regression.

A modeling exercise also was done considering an average temperature for all Alloy 182 SCC tests, of $314.9^{\circ} \mathrm{C}$ : as expected it showed data scattering, since the temperature is a very sensitive parameter which never should be considered constant [1].

9) It was done a Reliability Calculation Worksheet applicable to CDTN data modeling, using the described model semi-empiric-probabilistic [7]. This worksheet allows immediate information about PWSCC failure/initiation time reliability in considered tests. It was constructed based on a similar worksheet proposed by Dorner [8].

It is based in the Weibull reliability equation (4) [8].

$$
R(t)=\exp \left[-\left(\frac{x}{\alpha}\right)^{\beta}\right]
$$

with: $R(t)=$ reliability as test time function, $\alpha=$ life characteristic of the adjusted Weibull distribution, $\beta=$ Weibull shape parameter, $x=$ failure initiation time.

The data used to build the worksheet were as following:

a) Alfa and Beta - parameters according to the Table 2 [7]. b) The probability values to failure occurrence and reliability obtained in this worksheet are according to the Table 3.

Table 2: Alfa and Beta - Parameters According to the Weibull Distribution for Data Tests with Alloy 182 at $303^{\circ} \mathrm{C}$ [7]

\begin{tabular}{|l|l|}
\hline Alfa (Life Characteristic) & 394.8527766 \\
\hline Beta (Shape Parameter) & 12.92999549 \\
\hline
\end{tabular}

Table 3: Occurrence Probability to PWSCC Initiation and Reliability Parameters According to the Weibull Distribution for Data Tests with Alloy 182 at $303^{\circ} \mathrm{C}[7]$

\begin{tabular}{|c|c|c|}
\hline Test Time (h) & Occurrence Probability & Reliability \\
\hline \hline 100.0 & $1.94131 \mathrm{E}-08$ & 0.999999981 \\
\hline 200.0 & 0.000151488 & 0.999848512 \\
\hline 300.0 & 0.028252883 & 0.971747117 \\
\hline 400.0 & 0.693427928 & 0.306572072 \\
\hline 500.0 & 0.999999999 & $6.3804 \mathrm{E}-10$ \\
\hline 600.0 & 1 & 0 \\
\hline 700.0 & 1 & 0 \\
\hline 800.0 & 1 & 0 \\
\hline 900.0 & 1 & 0 \\
\hline 1000.0 & 1 & 0 \\
\hline
\end{tabular}

Note that, in the CDTN test conditions, from 600 hours of time testing, the probability to failure occurrence by PWSCC is equal to 1 (maximum 
PWSCC susceptibility), and the reliability is equal to 0 (minimum PWSCC resistance).

\section{DISCUSSION}

1) The preliminary modeling was performed with the semi-empiric-probabilistic model. The test data may be better adjusted in the deterministic mode using an activation energy at an average value at $325^{\circ} \mathrm{C}$, the exponent value of " $n$ " equal to -7 , that was estimated based on an article of a particular test different from CDTN test, and the values of true stress were all considered with a mean value of $450 \mathrm{MPa}$, except for CDTN test number 29. The deterministic modeling showed small deviations for two thirds of the data and large deviation for one third of the data.

2) For a modeling including the probabilistic approach (based in a Weibull distribution), further testing would be desirable, e.g. to $303^{\circ} \mathrm{C}$, to this adjustment is better consolidated and to check their level of reproducibility: one suggests that they be made at least 4 more PWSCC tests in the alloy 182 at $303^{\circ} \mathrm{C}$.

3) For three tests of Alloy 182 at $303^{\circ} \mathrm{C}$, there was not scattering, on the contrary, there was a reasonable deterministic setting (parameter $\beta$ very high, well above 4 [8]), whereas the PWSCC tests, regardless of the materials tested, already have tendency to give nonreproducible results, due to scattering. Usually in PWSCC tests of $\mathrm{Fe}-\mathrm{Ni}-\mathrm{Cr}$ alloys, the parameter " $\beta$ " is between 1 and 4, according to Staehle [9] (a broad and deep work that is almost a technical recommendation ("guideline") for the application the semi-empiricprobabilistic model).

4) In the tests provided by CDTN it is not clear how it was obtained the crack initiation time: from an inspection that detects crack of $10 \mu \mathrm{m}$ or $20 \mu \mathrm{m}$ ? It may be advisable to obtain a standardization of the time of initiation by a linear interpolation suggested by Figure 4 [10].

It should be used Eq. (5).

$t_{0}=t_{f}-\frac{a_{f}-a_{0}}{\frac{a}{t}}$

with: $t_{0}=$ initiation time, $t_{f}=$ failure time, $a_{f}=$ crack length in the considered failure time, $a_{0}=$ crack length at initiation time, $a / t=$ estimated average crack propagation rate considering standard deviation equal to $+2 S_{e}[10]$.

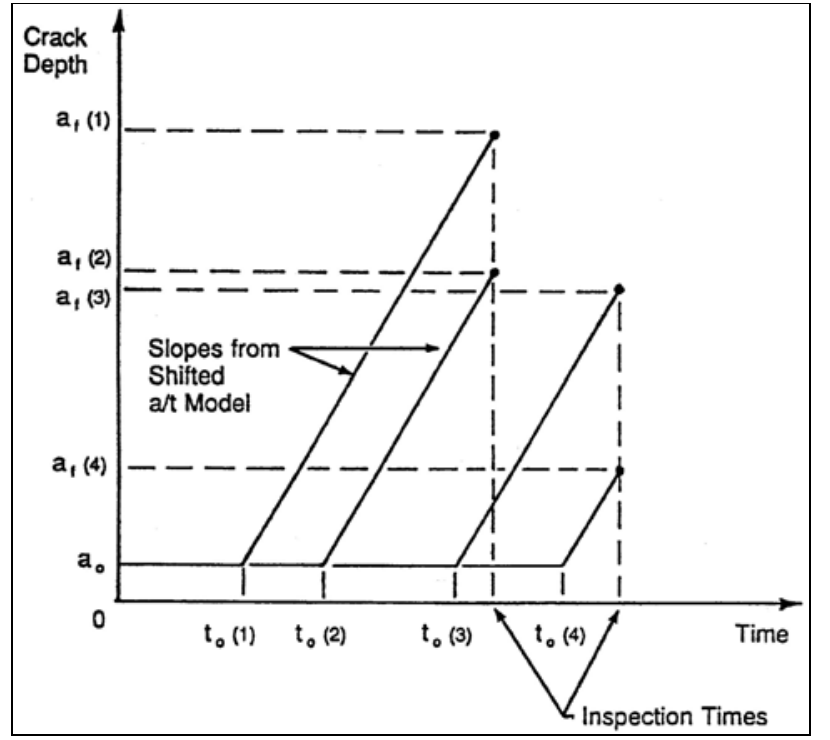

Figure 4: Schematic procedure to estimate time to initiation. From Pathania et al. [10].

Table 4: Key Factors for Consideration in Tests and Data Reporting. Adapted from MRP-115 [11]

\begin{tabular}{|c|c|}
\hline 1 & $\begin{array}{l}\text { Material within specifications including } \\
\text { composition/condition/heat treatment }\end{array}$ \\
\hline 2 & Mechanical strength properties \\
\hline 3 & ASTM specimen size criteria and degree of plastic constraint \\
\hline 4 & $\begin{array}{l}\text { Pre-cracking technique (including straightness criteria, } \\
\text { plastic zone size, crack morphology) }\end{array}$ \\
\hline 5 & $\begin{array}{l}\text { Special requirements for testing welds (e.g. pre-crack } \\
\text { location, residual stresses/strains) }\end{array}$ \\
\hline 6 & $\begin{array}{l}\text { Environment (chemistry, temperature, electrochemical } \\
\text { potential (ECP), flow rate at specimen, neutron/gamma flux) }\end{array}$ \\
\hline 7 & $\begin{array}{l}\text { Loop configuration (e.g., once-through, refreshed, static } \\
\text { autoclave) }\end{array}$ \\
\hline 8 & $\begin{array}{l}\text { Water chemistry confirmation by analysis (e.g., } \mathrm{Cl}, \mathrm{SO}_{4}, \mathrm{O}_{2} \text {, } \\
\mathrm{Cr} \text {, total organic carbon (TOC), conductivity) }\end{array}$ \\
\hline 9 & $\begin{array}{l}\text { Active constant or cyclic loading versus constant } \\
\text { displacement loading (e.g., using wedge) }\end{array}$ \\
\hline 10 & $\begin{array}{l}\text { On-line measurement of crack length versus time during test } \\
\text { (including precision) }\end{array}$ \\
\hline 11 & $\begin{array}{l}\text { Actual crack length confirmed by destructive examination } \\
\text { (assessment method/mapping) }\end{array}$ \\
\hline 12 & $\begin{array}{l}\text { Appropriateness of crack characteristics (fraction SCC along } \\
\text { crack front, uniformity, adequate SCC increment, } \\
\text { transgranular portions within IGSCC fracture surface, etc.) }\end{array}$ \\
\hline 13 & $\begin{array}{l}\text { Possible effects of changes in loading or chemistry } \\
\text { conditions during a test (including heat up and cool down) }\end{array}$ \\
\hline 14 & Calculation and reporting of $K$ or $\Delta K$ values \\
\hline 15 & Reporting of raw a vs. $t$ data and derivation of $d a / d t$ values \\
\hline 16 & $\begin{array}{l}\text { Reproducibility of data under nominally identical test } \\
\text { conditions }\end{array}$ \\
\hline
\end{tabular}

5) Finally it should be provided test standardization as showed in the Table 4 [11], to minimize scattering, and to allow better accuracy in the results. 


\section{CONCLUSIONS}

It was presented a modeling study following a methodology to adjust and to analyze data provided by CDTN from PWSCC tests of Alloy 182 extracted from reactor material weld with stainless steel 316 of Lemoniz, Spain. The analysis was based on the deterministic and probabilistic approach using the very general semi-empiric-probabilistic model, which may be applied for majority of the initiation cases. It generates an Excel Worksheet, which could be applied to the most of cases. In the Discussion section were given some suggestions for improvement of this modeling methodology.

\section{ACKNOWLEDGEMENTS}

ABEN (Associação Brasileira de Energia Nuclear): this technical contribution has been originally published (with few modifications) in the Proceedings of the INAC 2013- International Nuclear Atlantic Conference, November 24-29, 2013, held in Recife - PE - Brazil edited by the Associação Brasileira de Energia Nuclear-ABEN; Capes (Coordenação de Aperfeiçoamento de Pessoal de Nível Superior - Brazil) for this research fund, IPEN/CNEN-USP (Instituto de Pesquisas Energéticas e Nucleares/ Conselho Nacional de Energia Nuclear - Brazil), and CDTN/CNEN-UFMG (Centro de Desenvolvimento da Tecnologia Nuclear/ Conselho Nacional de Energia Nuclear - Brazil), for this research opportunity and infrastructure.

\section{REFERENCES}

[1] Aly OF. Analysis and Preliminary Modeling of Alloy 182 Data-CDTN. (Análise e Modelagem Preliminar de Dados de liga 182 - CDTN). São Paulo: IPEN, February 2009; 12. plus attached files (Internal Report).

[2] Schvartzman MMAM, Neves CFC, Matias A, Lourenço LI. Susceptibility Evaluation to Stress Corrosion Cracking of Inconel 600 MA in Nuclear Reactor Environment (Avaliação da susceptibilidade à corrosão sob tensão do Inconel 600 MA em ambiente de reator nuclear). In: Proceedings of
Anual Congress of ABM-International, 60, 2005, Belo Horizonte.... Belo Horizonte: ABM -Associação Brasileira de Metalurgia, Materiais e Mineração 2005.

[3] Staehle RW. Combining design and corrosion for predicting life. In: R.N. Parkins (Ed.), Life Prediction of Corrodible Structures, Vol. 1, NACE International, Houston 1994; pp. 138-291.

[4] White GA, Nordmann NS, Hickling J, Harrington CD. Development of Crack Growth Rate Disposition Curves for Primary Water Stress Corrosion Cracking (PWSCC) of Alloy 82, 182, and 132 Weldments. In.: Proceedings of the 12th International Conference on Environmental Degradation of Materials in Nuclear Power System - Water Reactors Edited by T.R. Allen, P.J. King, and L. Nelson TMS (The Minerals, Metals \& Materials Society) 2005.

[5] Scott $P$, Foucault M, Brugier B, Hickling J, Mcllree A. Examination of Stress Corrosion Cracks in Alloy 182 Weld Metal After Exposure to PWR Primary Water. In.: Proceedings of the 12th International Conference on Environmental Degradation of Materials in Nuclear Power System - Water Reactors - Edited by T.R. Allen, P.J. King, and L. Nelson TMS (The Minerals, Metals \& Materials Society) 2005; pp. 497-509.

[6] IAEA. Assessment and management of ageing of major nuclear power plant components important to safety: Pressurized water reactor pressure vessels. Vienna: IAEA 1997.

[7] Aly OF. Analysis and Preliminary Modeling of Alloy 182 Data Complement- CDTN. (Complemento da Análise e Modelagem Preliminar de Dados de liga 182 - CDTN). São Paulo: IPEN, March 2009; 5 p. (Internal Report).

[8] Dorner WW. Using Microsoft Excel for Weibull Analysis. QCI International (USA), 1999; Access on August 2012: http://www.qualitydigest.com/jan99/html/body_weibull.html

[9] Staehle RW. Bases for Predicting the Earliest Penetrations Due to SCC for Alloy 600 on the Secondary Side of PWR Steam Generators. Washington, DC: USNRC, 2001. (NUREG/CR-6737 ANL-01/20 RWS 151 Report), Access on August 2013: http://adamswebsearch2.nrc.gov/idmws/ doccontent.dll? library=PU_ADAMS^PBNTAD01\&ID=004026 229 or http://www.nrc.gov/reading-rm/doc-collections/nuregs/ pubs/ (input ADAMS number ML012610214 (September, 2001).

[10] Pathania RS, Gelpi A, Foucault M, Stuckey K, Fyfitch S, Sarver JM. Stress Corrosion Cracking of Welding Alloy 600 Mockups. EPRI: Palo Alto, CA, 1997 (TR-104831).

[11] White G, Gorman J, Nordmann N, Jones P, Kreider M, Hickling J. Materials Reliability Program Crack Growth Rates for Evaluating Primary Water Stress Corrosion Cracking (PWSCC) of Alloy 82, 182, and 132 Welds. (MRP-115-EPRI 1006696 Final Report) Dominion Engineering, Inc.: Reston, VA, November 2004, Access on August 2013: http://www.epriweb.com/public/000000000001006696.pdf

(C) 2014 Aly et al.; Licensee Lifescience Global.

This is an open access article licensed under the terms of the Creative Commons Attribution Non-Commercial License (http://creativecommons.org/licenses/by-nc/3.0/) which permits unrestricted, non-commercial use, distribution and reproduction in any medium, provided the work is properly cited. 